\title{
PERCEPÇÃO AMBIENTAL DE DIFERENTES ATORES SOCIAIS SOBRE O LAGO DO ABREU EM FORMOSA - GO
}

\author{
Rodrigo Capelle SUESS ${ }^{1}$, Rafael Gonçalves BEZERRA ${ }^{2}$ e Hugo de CARVALHO SOBRINHO ${ }^{3}$ \\ ${ }_{1,3}^{1,}$ Universidade Estadual de Goiás - Unidade Universitária de Formosa \\ ${ }^{2}$ Instituto Federal de Educação, Ciência e Tecnologia de Goiás - Câmpus Formosa \\ E-mail: rodrigo.capellesuess@gmail.com ${ }^{1}$
}

Artigo submetido em fevereiro/2013 e aceito em dezembro/2013

\section{RESUMO}

Pesquisas sobre percepção ambiental são importantes para investigação de conhecimentos, valores, opiniões, atitudes e expectativas que as pessoas têm em relação ao seu local de moradia, visto que cada ser humano percebe, reage e responde de maneira diferente ao ambiente em que vive. Neste sentido, o presente trabalho teve por objetivo analisar a percepção ambiental dos diferentes atores sociais sobre o Lago do Abreu em Formosa-GO. Para isso, foram realizadas entrevistas semiestruturadas tanto com moradores quanto com frequentadores do local, além de registros fotográficos e observações realizadas no local de estudo. Os principais problemas expostos pelos entrevistados foram descuido e descaso com a paisagem, com a infraestrutura, com a segurança, com o meio ambiente e com a limpeza. Estes problemas foram constantemente atribuídos ao Poder Público como o principal gerador. Nessa perspectiva, espera-se que o poder público e os moradores assumam o compromisso de zelar por esta importante área cultural arraigada de sinais de sua identidade, localizada no município de Formosa-GO.

PALAVRAS-CHAVE: Percepção ambiental, urbanização, paisagem.

\section{ENVIRONMENTAL PERCEPTION OF THE DIFFERENT SOCIAL ACTORS ABOUT THE ABREU'S LAKE IN FORMOSA - GO}

\begin{abstract}
Researches about environmental perception are important for investigations of knowledge, values, beliefs, attitudes and expectations that people have about their place of residence, since every human being perceives, reacts and responds differently to the environment in which they live. In this sense, the present study aimed to analyze the environmental perception of the different social actors about the Abreu's Lake in Formosa-GO. For this, we conducted semi-structured interviews with both locals and regulars
\end{abstract}

to the place, and photographic records and observations held in place. The main problems identified by respondents were carelessness and neglect of the landscape, with the infrastructure, security, the environment and cleaning. These problems were constantly allocated to the Government as the main generator. In this perspective, it is expected that the government and residents commit to take care this important place of the municipality of Formosa-GO.

KEYWORDS: Environmental perception, urbanization, landscape. 


\section{ENVIRONMENTAL PERCEPTION OF THE DIFFERENT SOCIAL ACTORS ABOUT THE ABREU'S LAKE IN CITY OF FORMOSA - GO}

\section{INTRODUÇÃO}

Atualmente, a dinâmica das ações antrópicas têm contribuído significativamente para acentuar a crise socioambiental. Os avanços tecnológicos, apesar de proporcionar melhores condições de existência para a humanidade, têm contribuído para a cristalização de um modelo socioeconômico insustentável. Vê-se, portanto, um mundo firmemente suspendido sob as rédeas do capitalismo e é preocupante a forma como os recursos naturais e culturais de nosso país vêm sendo tratados.

Como consequência, vivenciamos múltiplas transformações no espaço, que de uma forma ou de outra se unem e se separam em velocidades e dinâmicas únicas, as quais envolvem o espaço e o tempo, além de dependerem do jogo de interesses e intencionalidades de indivíduos ou grupos sociais. Entender essas transformações se torna fundamental para a compreensão e a explicação de pontos chaves para montar o quebra-cabeça de dilemas, aflições, angústias e alienações que cercam, dão subsídios ou limitam certos indivíduos ou grupos em suas relações econômicas, biológicas, políticas e sociais.

Primeiramente, é necessário considerar que a cultura é a chave para a compreensão sistemática de diferenças e semelhanças entre os homens (WAGNER \& MIKASSEL, 2003). Ela se manifesta como um meio de comunicação do homem com o universo, sendo assim, um aprendizado das relações entre o homem e o meio.

Portanto, podemos dizer que a cultura implica em como o homem percebe e atua no espaço, atuação essa que se percebe na paisagem, pois, qualquer sinal da ação humana numa paisagem implica cultura (SANTOS, 2012a; WAGNER \& MIKESSEL, 2003). Através de uma imagem aparentemente imóvel, a paisagem revela um conjunto dotado de sentidos e o ser humano se identifica com os espaços da vida notados por meio da paisagem (CARLOS, 2007).

Para isso muitas vezes entender a percepção de ambiente nos dá contribuições de grande valia para partir para o global. Aspectos relacionados à temática ambiental vêm se tornando cada vez mais discutidos e ganham destaque no cenário mundial. No entanto, ainda não é tão evidente a compreensão que as pessoas têm sobre o assunto, principalmente com relação a real dimensão das variáveis ambientais e seus efeitos sobre o ambiente como um todo (BARROS, 2012).

A educação e a percepção ambiental despontam como armas na defesa do meio natural e ajudam a reaproximar o homem da natureza, garantindo um futuro com mais qualidade de vida para todos, já que despertam maior responsabilidade e respeito dos indivíduos em relação ao ambiente em que vivem (FERNANDES \& PELISSARI, 2003).

Estudos que abordem a temática de percepção ambiental se justificam porque a sociedade e o Estado têm a incumbência de preservar o meio ambiente. Assim dispõe a Constituição Federal de 1988, em seu Artigo 225, estabelecendo que "Todos têm direito ao meio ambiente ecologicamente equilibrado, bem de uso comum do povo e essencial à sadia qualidade de vida, impondo-se ao poder público e à coletividade o dever de defendê-lo e preservá-lo às presentes e futuras gerações". Além disso, estudos com esse escopo dão contribuições 
importantes para a investigação de conhecimentos, valores, opiniões, atitudes, expectativas que as pessoas têm em relação ao seu local de moradia, visto que cada ser humano percebe, reage e responde de maneira diferente ao ambiente em que vive.

De acordo com a UNESCO (1973), uma das dificuldades para a conservação de ambientes naturais está presente nas várias percepções e valores que são atribuídos ao ambiente, entre indivíduos de culturas e classes sociais diferentes que têm papeis distintos nesses ambientes.

Dessa maneira, a percepção ambiental pode ser definida como sendo uma tomada de consciência do ambiente pelo homem, ou seja, o ato de perceber o ambiente que se está inserido, aprendendo a proteger e a cuidar do mesmo. Já para Whyte (1978), percepção ambiental é entendida como uma tomada de consciência e a compreensão pelo homem do meio ambiente no sentido mais amplo, envolvendo bem mais que uma percepção sensorial individual, como a visão ou a audição.

Tuan (1980) explica que percepção envolve tanto a resposta dos sentidos aos estímulos externos como a atividade proposital. Muito do que as pessoas percebem tem determinado valor individual, para a sobrevivência biológica e para propiciar alguns contentamentos que estão arraigados na cultura. A dimensão da paisagem é a dimensão da percepção, no qual o aparelho cognitivo tem relevante importância, e através da nossa seletividade é captada e construída pelos sentidos.

Segundo Lermen (2008) a percepção ambiental está intimamente ligada à cultura, história, tempo, experiência e espaço de cada pessoa. A autora ainda ressalta que a percepção ambiental não se restringe a investigar o que é natureza, mas notar que a interação entre as pessoas em si atinge e direciona a convivência com ela e vice-versa.

Com efeito, entender o modo pelo qual os moradores percebem sua paisagem é de grande valia para a compreensão da forma com que cada indivíduo interage com o meio ambiente. Assim, a paisagem se torna uma forma de compreensão e de compreender como atores e reinventores do espaço percebem e transformam o mundo, em especial ao que é tangível e experienciado pela totalidade dos sentidos. Segundo a fala de Santos (2012b, p. 68), "tudo aquilo que nós vemos, que nossa visão alcança, é a paisagem. Esta pode ser definida como o domínio visível, aquilo que a vista abarca. Não é formada apenas de volumes, mas odores, cores e sons".

Ainda segundo Santos (2012b) a realidade é tida como única e cada pessoa a vê de maneira singular, então a visão do homem para com as coisas materiais é sempre deformada. Assim cada pessoa tem uma atitude diferente frente às condições do meio em que vive. Isso reflete em suas expectativas, percepções, julgamentos, afeição ou desafeição que constituem o comportamento pessoal ou coletivo, muitas vezes inconscientemente.

O presente estudo foi desenvolvido na cidade de Formosa-GO, em cujo perímetro urbano situam-se importantes nascentes as quais compõem a Bacia Hidrográfica do São Francisco que, em alguns bairros da cidade, alimentam lagos, criados para represar a água provinda de nascentes. Um deles, chamado Lago do Abreu, situa-se em meio a três bairros da cidade e concentra muitas residências à sua margem. Assim, observando a importância do estudo das percepções ambientais das pessoas, que constroem e resignificam à história do Lago do Abreu, o presente trabalho teve por objetivo analisar a percepção ambiental dos diferentes atores sociais sobre o Lago do Abreu em Formosa-GO. 


\section{METODOLOGIA}

\subsection{Caracterização da área de estudo}

O município de Formosa (Figura 1), segundo o dispõe o seu Plano Diretor do ano de 2003, situa-se na latitude $15^{\circ} 32^{\prime} 14^{\prime \prime S}$ e longitude $47^{\circ} 20^{\prime} 04^{\prime \prime} \mathrm{W}$, com altitude média de $918 \mathrm{~m}$. Possui vegetação típica do Cerrado e, segundo a classificação de climática Köppen, apresenta clima tropical Aw, com verão úmido e déficit hídrico no inverno. Formosa possui 100.085 habitantes, de acordo com o censo do Instituto Brasileiro de Geografia e Estatística (IBGE) de 2010. A economia do município é predominantemente voltada ao setor de serviços. O Índice de Desenvolvimento Humano Municipal (IDH-M) do ano 2010 é de 0,744, considerado de médio desenvolvimento humano, segundo o Atlas de Desenvolvimento Humano do ano 2013 realizado pelo Programa das Nações Unidas para o Desenvolvimento no Brasil (PNUD, 2013).

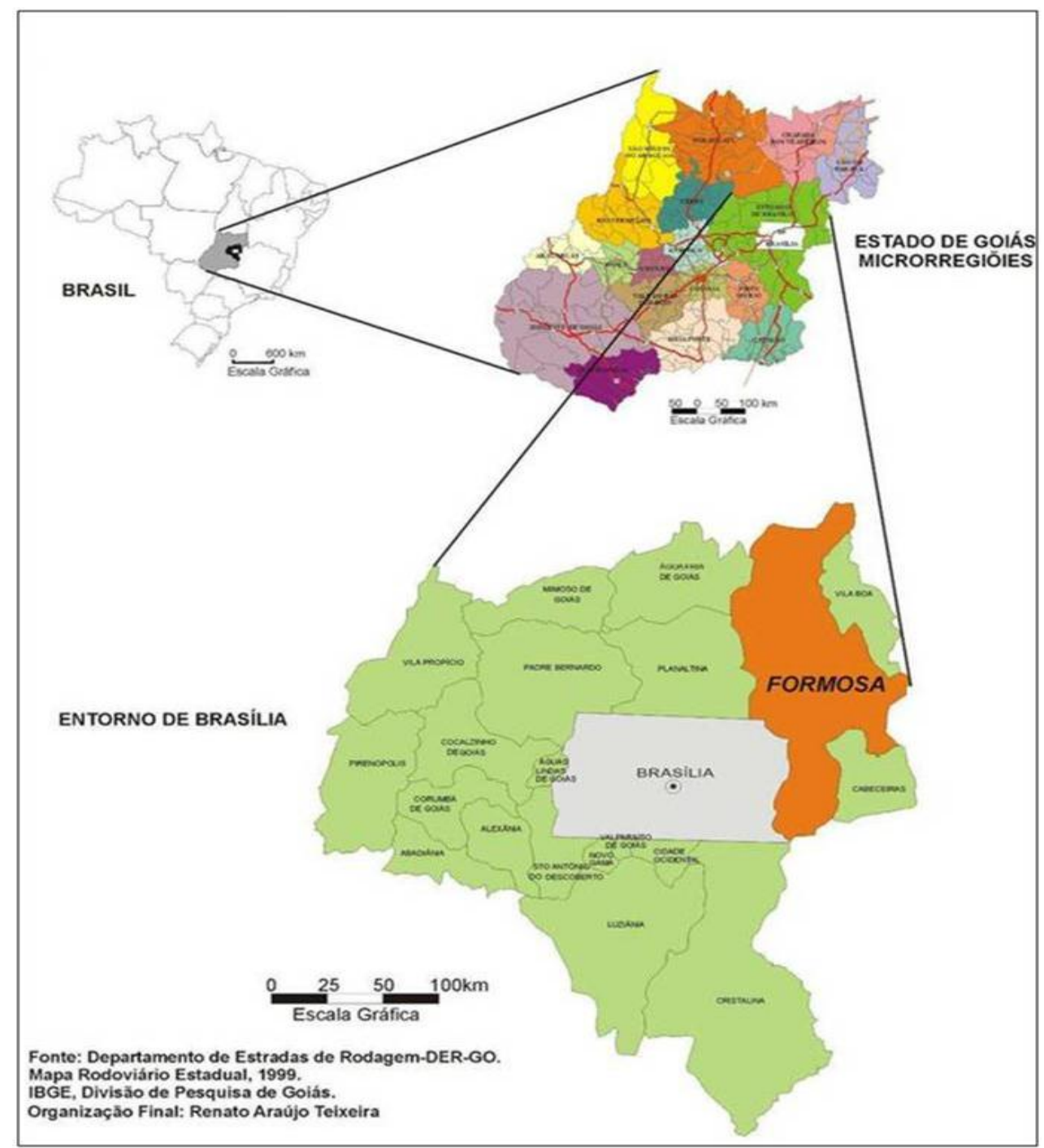

Figura 1 - Localização do município de Formosa - GO em relação ao entorno de Brasília. (Fonte: Teixeira, 2005.)

O município se enquadra na mesorregião do Leste goiano e na microrregião do Entorno de Brasília. A sede do município se localiza a 79 km da Capital Federal e a $280 \mathrm{~km}$ de Goiânia. Devido, principalmente, à proximidade da primeira cidade depara-se com grande fluxo migratório, destacando-se o pendular, o que acaba gerando especulação imobiliária e por vezes 
ocupação desordenada. Atualmente o município - juntamente com outros do entorno do Distrito Federal - faz parte da Região de Desenvolvimento Integrado do Distrito Federal e Entorno (RIDE).

Formosa conta com diversas festas populares, dentre as quais a Festa do Divino Espírito Santo, a mais importante da cidade, em que todas as expressões acima podem ser consideradas como um testemunho de uma vida cultural, mesmo antes de Brasília (SILVA, 2011). Conta também com patrimônios naturais, como a Toca da Onça, o Buraco das Araras, a Cachoeira de Itiquira, a Lagoa Feia e, dentre outros, o patrimônio arqueológico denominado Sítio Arqueológico de Bisnau.

No entanto, os locais situados no perímetro urbano da cidade são frequentemente ignorados tanto no que concerne ao desenvolvimento de pesquisas como também por parte por parte dos moradores e do Poder Público Municipal. Nesse sentido, cabe destacar que a própria modificação (ou modelamento conforme interesses do homem) da paisagem de Formosa passou e ainda passa despercebida e, muitas vezes, acaba perdendo a identidade na história do local e do município.

Nessa perspectiva, de modificação da paisagem natural da cidade, insere-se o Lago do Abreu, situado na cidade de Formosa-GO. Dessa forma, o presente estudo foi realizado em três bairros: Setor Abreu, Jardim das Américas e Vila lara. O lago, que é foco do presente estudo, é denominado Lago do Abreu, também conhecido entre os moradores como Lago da Vovó, localiza-se no perímetro urbano da cidade, na divisão dos três bairros citados anteriormente e caracteriza-se por ocupação residencial circunvizinha à sua delimitação.

O Lago do Abreu é sustendo por algumas nascentes, porém, no período da seca, o volume da água é reduzido, o que facilita o crescimento de gramíneas e assoreamento do local. A Figura 2 mostra o Lago do Abreu no período seco e chuvoso.

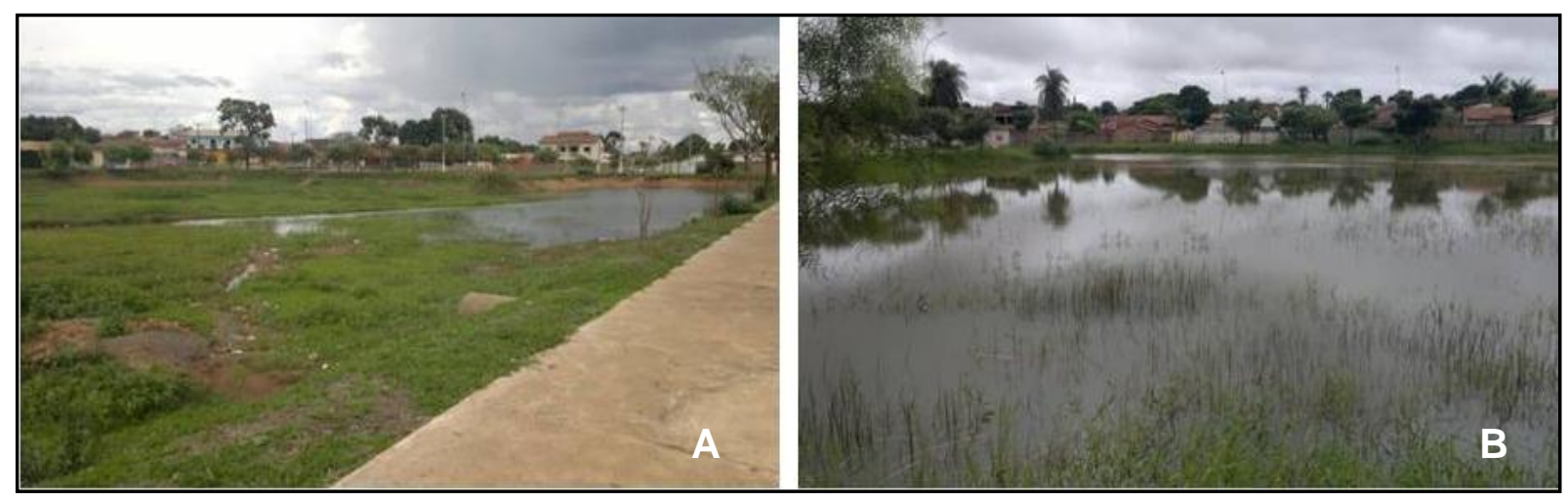

Figura 2 - Lago do Abreu (A) no período de escassez hídrica e (B) no período chuvoso. (Fotos dos Autores.)

Em 2010, por meio do Decreto Municipal N. ${ }^{\circ} 1977$, de 20 de dezembro, a área em que se situa o Lago do Abre, e suas respectivas nascentes, foram declaradas de utilidade pública, devendo ocorrer à desapropriação do local em até cinco anos da data de publicação do diploma normativo. Além disso, há um Termo de Compromisso e Ajustamento de Conduta (TAC), firmado entre o Ministério Público do Estado de Goiás, a Prefeitura Municipal de Formosa e uma empresa particular no ano de 2010. Segundo o teor do documento, cabe à última recuperar a área degradada, juntamente com a sua fitofisionomia, até outubro de 2013 , respeitados os 
procedimentos legais de aprovação dos órgãos ambientais competentes. O TAC prevê ainda a implantação do Parque Municipal Ecológico Lagoa do Abreu na cidade de Formosa-GO e os recursos de seu financiamento devem ser providos pela empresa privada, por meio de recursos de indenização.

Fica clara, portanto, a importância que o Lago do Abreu tem para a preservação do meio ambiente local e, nesse sentido, a percepção dos diferentes atores sociais acerca de seu meio consiste também em uma avaliação de sua atual situação.

\subsection{Coleta de dados}

Tuan (1980) denominou a relação de afetividade que os humanos estabelecem mutuamente com o meio ambiente natural de topofilia. Com efeito, fez-se um recorte do espaço a fim de redescobri-lo através da melhor fonte possível: os moradores, que carregam entre si historicidade e percepções de sua relação com o meio refletindo o seu mundo vivido e relações culturais estabelecidas.

Esta pesquisa foi desenvolvida com uma abordagem quanti-qualitativa por se mostrar a mais adequada para a obtenção e análise dos dados pretendidos. De acordo com Marconi \& Lakatos (2011), na metodologia quantitativa, os pesquisadores valem-se de amostras e de informações numéricas para medir opinião e atitudes. Já o enfoque qualitativo foi utilizado na observação simples do ambiente pesquisado e na análise dos depoimentos dos entrevistados, pautando-se na técnica de análise de conteúdo. Optou-se também por transcrever algumas respostas dos participantes, quando se julgou pertinente.

Como modalidade de pesquisa, adotou-se o estudo de caso. O estudo de caso, segundo Gil (1999), caracteriza-se por um estudo delimitado e profundo, com o fito de se adquirir um conhecimento amplo e detalhado de um ou poucos objetos de estudo.

A pesquisa junto a 22 moradores do Lago do Abreu foi realizada entre os meses de outubro e novembro de 2012, tendo-se como referência o "critério de saturação" (SÁ, 1998). À medida que as respostas dos entrevistados começaram a se repetir, optamos por parar com as entrevistas, pois repostas repetidas não seriam significativas para cumprir os objetivos do presente estudo.

A coleta de dados juntos aos participantes da pesquisa se deu por meio de entrevistas semiestruradas e registro fotográficos. Optamos pela técnica da entrevista neste estudo, pois, segundo Gil (1999), para obtenção de informações sobre o que as pessoas sabem, quais as opiniões que têm sobre algum fato, desejos pessoais, etc., a entrevista se mostra adequada para tal finalidade. Segundo Minayo (2007), a entrevista possibilita combinações entre perguntas objetivas e subjetivas, nas quais a pessoa entrevistada encontrará meios de ponderar sobre o assunto em questão.

Entre os dados obtidos através das entrevistas procurou-se caracterizar o perfil dos entrevistados, tais como a idade, sexo, profissão, nível de escolaridade, assim como a sua percepção de como o espaço transformado é utilizado, a limpeza do local e outras informações permitindo a percepção do ambiente pelos sujeitos pesquisados. 


\section{RESULTADOS E DISCUSSÕES}

\subsection{Perfil dos entrevistados}

A pesquisa envolveu 22 moradores circunvizinhos e frequentadores do Lago do Abreu, sendo 12 mulheres e 10 homens cujas idades compreendiam a faixa etária entre os 14 e 75 anos. Os dados referentes ao sexo da população dos sujeitos entrevistados estão representados na Figura 3.

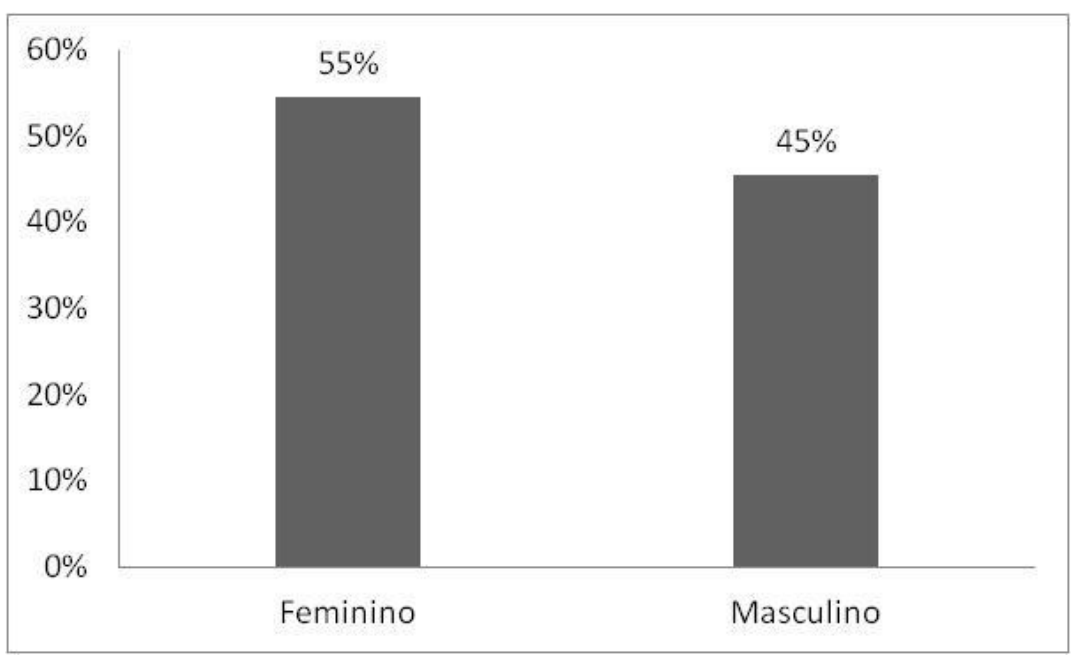

Figura 3 - Sexo da população da população entrevistada.

Após a análise dos dados observou-se que a maioria, 55\%, dos entrevistados eram do sexo feminino. Esta predominância ocorreu em função da maior presença de mulheres nas residências, nos horários em que as entrevistas foram realizadas. Estes resultados são semelhantes aos encontrados por Mansano et al. (2011), os quais em trabalho referente ao estudo da percepção da paisagem de alguns frequentadores do Parque do Ingá na cidade de Maringá (PR), constataram que, no dia da coleta de dados, $52 \%$ dos entrevistados eram do sexo masculino enquanto $48 \%$ eram do sexo feminino. Já no estudo de Gehrke et al. (2011), a população masculina foi significativamente predominante, contribuindo com $78 \%$ dos entrevistados, enquanto $22 \%$ eram do sexo feminino.

Quanto ao nível de escolaridade relatada pelos entrevistados, os dados obtidos foram organizados nas seguintes categorias: Ensino Fundamental incompleto (EFI), Ensino Fundamental completo (EFC), Ensino Médio incompleto (EMI), Ensino Médio completo (EMC) e Ensino Superior incompleto (ESI). A Figura 4 apresenta a escolaridade dos entrevistados.

Diferentemente da pesquisa realizada por Mansano et al. (2011) em que 49\% dos entrevistados haviam concluído o Ensino Superior, no presente trabalho verificou-se que nenhum dos entrevistados relatou ter concluído a Educação Superior, porém $5 \%$, à época das entrevistas, cursavam a referida modalidade de ensino (ESI). Todavia percebeu-se que a maioria dos entrevistados (95\%) possui nível de instrução referente à educação básica, sendo que os níveis EFI e EMC abrangem, cada um, 32\% dos entrevistados; $5 \%$ dos pesquisados disseram possuir o EFC e, por fim, 27\% relataram estar cursando o Ensino Médio (EMI). Ressalta-se que nenhum dos entrevistados relatou ser analfabeto. Diferentemente, Bay \& Silva (2011) em trabalho sobre a percepção ambiental de moradores do bairro de Liberdade na cidade de Parnamirim (RN), 
constataram que $30 \%$ possuíam o Ensino fundamental incompleto, 33,34\% haviam concluído o Ensino Fundamental, 30\% concluíram o Ensino Médio e apenas 6,66\% eram analfabetos.

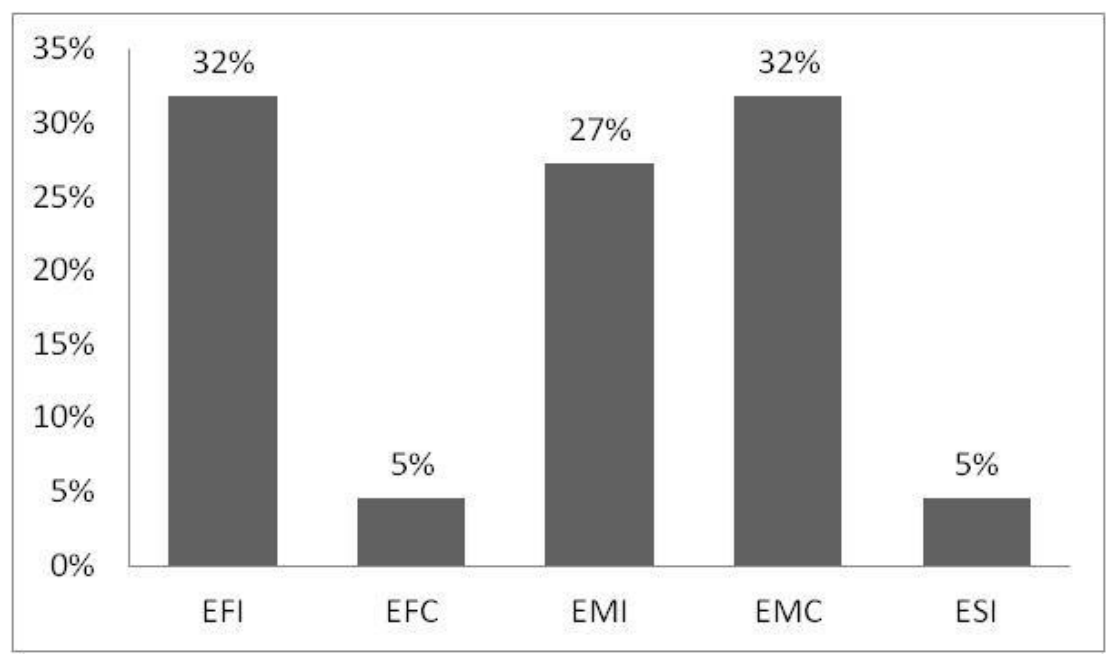

Figura 4 - Frequências do grau de instrução apresentado pelos moradores circunvizinhos do Logo do Abreu. Ensino Fundamental incompleto (EFI), Ensino Fundamental completo (EFC), Ensino Médio incompleto (EMI), Ensino Médio completo (EMC) e Ensino Superior incompleto (ESI).

No que tange à profissão, tem-se $31,8 \%$ estudantes, $18,1 \%$ são trabalhadores do Lar, $13,6 \%$ são aposentados, $9 \%$ são autônomos e $27,2 \%$ tinham outra ocupação, tais como acompanhante de idoso, babá, cabeleireira, vaqueiro e operador de empilhadeira. Já Bay \& Silva (2011) relatam que da maioria dos entrevistados, 30\%, correspondia a donas de casa; $3,33 \%$ consistiam de funcionários públicos, estudantes, microempresários, desempregados e aposentados; 16,66\% disseram ser funcionários de empresas privadas e $26,67 \%$ trabalharam como profissionais liberais.

Apenas $18,2 \%$ dos entrevistados colocaram que não frequentavam o Lago do Abreu. Por outro lado, observou-se que $81,8 \%$ dos pesquisados o visitam constantemente. Deste contingente, $50 \%$ frequentavam o lago com intuito de passeio ou lazer; $31,8 \%$ utilizam a localidade para a prática de exercícios físicos - caminhada, corrida, musculação; 18,2\% disseram que o Lago oferece opções para a realização de atividades educacionais como a aproximação com o desenvolvimento de práticas de Educação Ambiental ou disseram ser o Lago um local fecundo para o desenvolvimento de estudos pautados na fauna e flora local. Tais resultados permitem inferir que no Lago do Abreu se desenvolvem não apenas as atividades voltadas ao lazer; destacam-se, porém, outros usos desse ambiente, o que afirma a importância desse meio para os moradores da área e da cidade.

\subsection{Percepções sobre o Lago do Abreu}

A situação ambiental do Lago foi relatada, segundo $77,3 \%$ dos depoimentos, como péssima ou ruim, o que é evidenciado na Figura 4. 


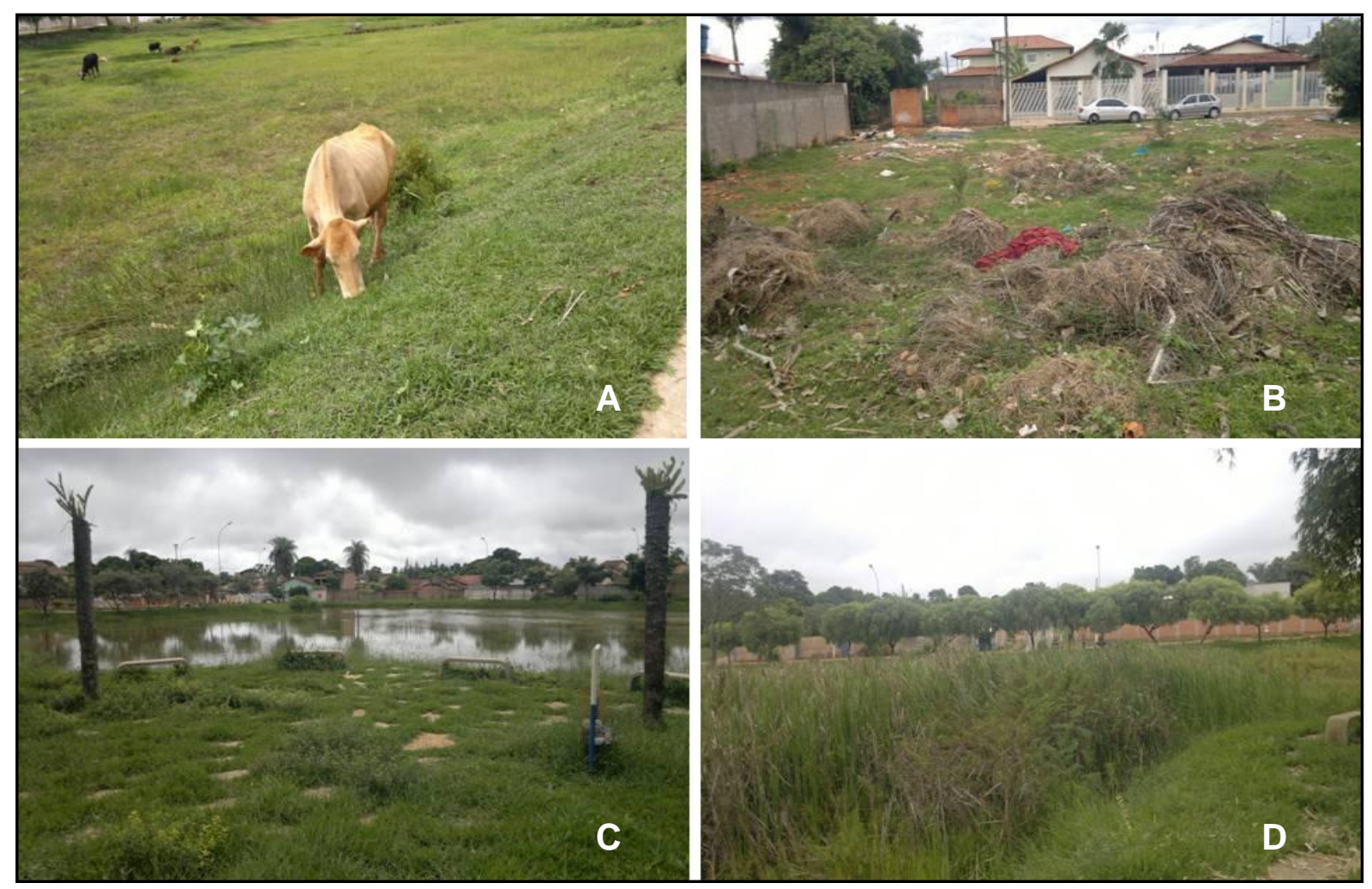

Figura 4 - Imagens das proximidades do Lago do Abreu. (A) O Lago serve para alimentar animais devido à quantidade de gramíneas que crescem no local. (B) Entulho indevidamente acumulado às margens do Lago. (C) Praça tomada pelo mato. (D) Matagal às margens do Lago. (Fotos dos Autores.)

Ainda referente à situação ambiental do Lago, constatou-se que é grande o crescimento de espécies exóticas em seus arredores, como gramíneas e bananeiras. Devido a isso, é comum que o Lago, no período do ano em que não está tomado pelas águas, seja apropriado para alimentação animal. Também é perceptível a grande quantidade de lixo no local, o que facilita a proliferação de mosquitos e animais peçonhentos, principalmente cobras e escorpiões.

As categorias de péssima e ruim para a situação ambiental do local também foram destacadas pelos entrevistados quando se indagou a respeito da representatividade ambiental do Lago do Abreu para a cidade de Formosa (Figura 5).

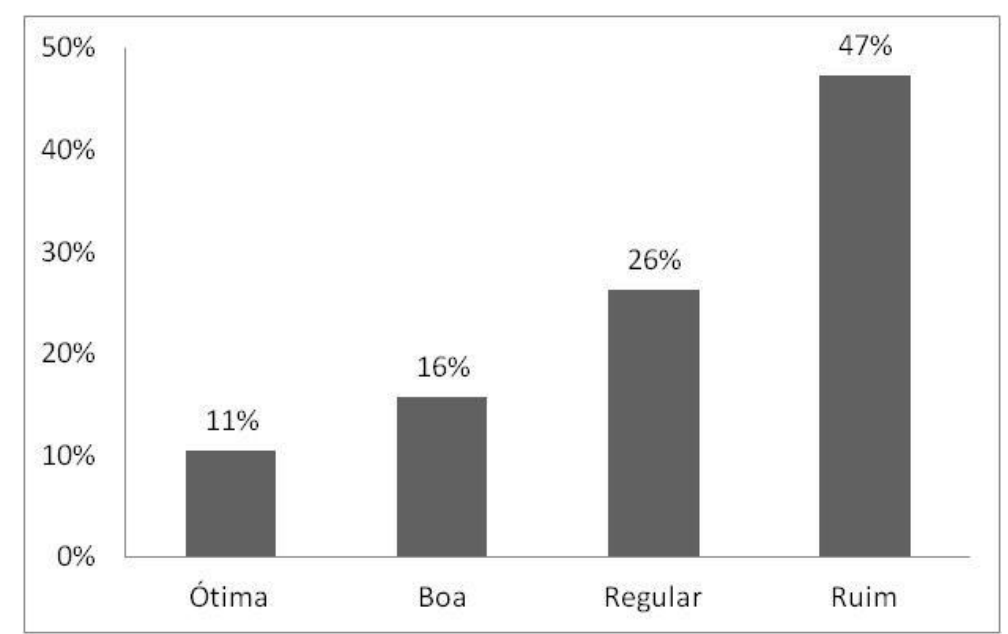

Figura 5 - Níveis atribuídos pelos entrevistados para representatividade do Lago do Abreu em termos de beleza paisagística para a cidade de Formosa-GO. 
Metade dos participantes da pesquisa (50\%) não destacou o local como representativo em termos paisagístico, urbanístico e de qualidade de vida em nível de município, resultado diferente ao encontrado por Mansano et al. (2011), em pesquisa realizada a respeito da percepção da paisagem de alguns frequentadores do Parque do Ingá na cidade de Maringá (PR), os quais constataram que $91 \%$ dos frequentadores do Parque o consideram como uma paisagem bonita. Esses resultados permitem-nos dizer que boa parte dos entrevistados não está contente com a situação ambiental do Lago do Abreu e diante de várias paisagens encontradas no município a mesma não se mostra relevante, permitindo, portanto, dizer que melhorias são necessárias como as apontadas nos depoimentos dos moradores a seguir: "devia aumentar a segurança local"; "melhoria de infraestrutura para o lazer da população"; "colocando áreas de esporte, estabelecimentos comerciais e atividades educacionais"; "Ter mais limpeza, segurança e iluminação".

Carvalho Sobrinho (2011) realizou um trabalho com o objetivo de comparar a percepção ambiental dos moradores circunvizinhos a dois outros lagos situados no perímetro urbano de Formosa, o Lago do Vovô e a Lagoa dos Santos. A autora constatou um maior grau de satisfação dos moradores circunvizinhos ao Lago do Vovô em detrimento da satisfação dos moradores circunvizinhos à Lagoa dos Santos. Assim, destaca que os entrevistados do Lago do Vovô mostraram-se mais satisfeitos com o zelo do Poder Público para com o espaço. Enquanto na Lagoa dos Santos os moradores não se apresentaram satisfeitos, principalmente em relação à segurança. Esta diferença de percepção pode estar emaranhada na questão da própria localidade do Lago do Vovô em relação à Lagoa dos Santos, pois o primeiro localiza-se praticamente no centro urbano, os serviços públicos encontram-se mais efetivos e com um público de maior poder aquisitivo; o segundo está localizado em zona periférica e com um público de menor poder aquisitivo.

Percebeu-se da comparação dos resultados da pesquisa realizada por Carvalho Sobrinho (2011) que as percepções dos atores sociais do Lago do Abreu com os atores sociais da Lagoa dos Santos são semelhantes quanto ao cuidado que o Poder Público tem para com esses locais. Tanto o Lago do Abreu quanto à Lagoa dos Santos por situarem-se em regiões periféricas ao centro da cidade podem, de certa forma, sofrer influência no que concerne ao oferecimento dos serviços públicos, que não se apresenta em contento para com os moradores.

Quando indagados sobre a percepção de mudança da paisagem no ambiente do Lago do Abreu, 50\% disseram que houve mudança na paisagem e no ambiente do Lago ao longo do tempo. Mas, ressalta-se que, de início, alguns dos entrevistados apresentaram dúvidas sobre tal questionamento. Apesar de a paisagem não ser estática (exceto quando a registramos por meio da fotografia ou até mesmo pela memória) e estar aberta para o presente e o futuro, ela constitui um conjunto de objetos concretos e subjetivos, que por vezes nos parece como simples descrições do real-aparente. Porém, ela está incumbida de múltiplas determinações, o que pode justificar a primeiro momento a dificuldade dos entrevistados sobre esse questionamento. (CARLOS, 2007; MOREIRA, 1994).

Alguns moradores colocam a culpa da não sustentação do Lago pela nascente nos desvios e na má conservação e destruição das áreas adjacentes à nascente. Outros acreditam ser algo natural, pois segundos muitos deles esse era um brejo e para amenizar os impactos da inundação na área de várzea foi "construído" e urbanizado o local, daí a percepção ambiental de cada ator social mostrar-se singular, com vieses subjetivos. 
Das alterações relatadas na paisagem do Lago pelos frequentadores, destacam-se a transformação do brejo em lago, ou seja, o local onde se situa atualmente o Lago do Abreu era uma área de várzea e foi modificado, o que vai ao encontro às justificativas para se realizar estudos de percepção ambiental. A Figura 6 retrata como se deu a modificação da paisagem do local onde está situado o Lago do Abreu num intervalo de nove anos.

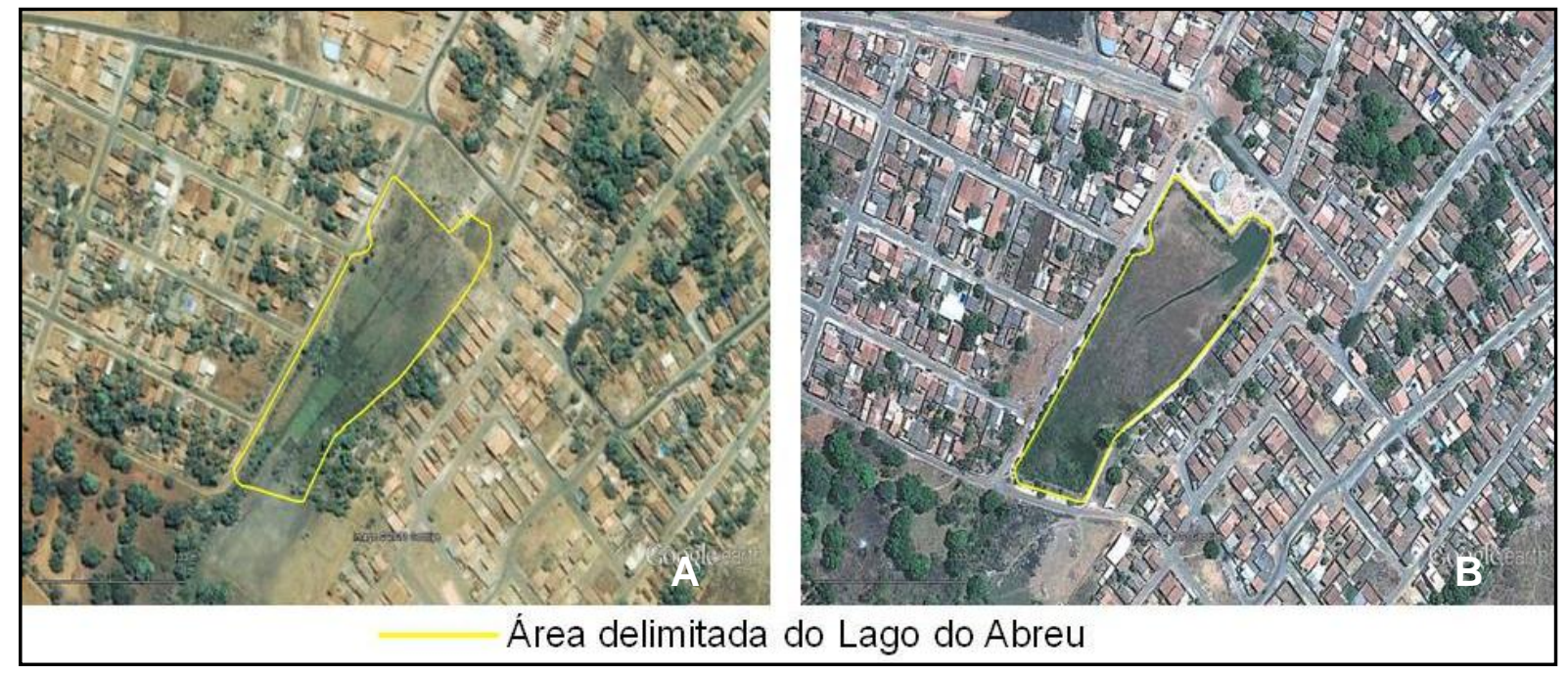

Figura 6 - Imagens de satélite disponibilizadas pelo Google Earth sobre a modificação da paisagem do local campo da pesquisa. (A) Imagem do Lago do Abreu no dia 15/09/2002. (B) Imagem do Lago do Abreu no dia 30/11/2011.

O processo de urbanização, a modificação ambiental da nascente do local e as diferentes intensidades de atenção dada pelo poder público ao longo do tempo também fizeram parte dos apontamentos dos participantes da pesquisa, conforme foi evidenciado no discurso dos entrevistados:

Eu acho que há de todos, tanto público quanto ao mau cuidado da população. 0 Lago precisa ser cuidado. Vejo também um descaso público perante esse abandono. No começo era cuidado por todos agora é largado, com tanto lixo e mato. [...] má conservação local, no começo era bonito.

Dos entrevistados, $86,3 \%$ eram moradores circunvizinhos do Lago. Deste percentual $52 \%$ moram há mais de 12 anos no local. Perguntados se diante da paisagem do Lago ocorreu à valorização de seus imóveis, mais de $73 \%$ acreditam que ocorreu valorização. Dentre os motivos apontados pelos moradores está a opção de lazer que o local oferece e a melhoria da paisagem do bairro. Segundo Carlos (2007) intervenção do Estado no espaço por diversos formas sejam as referentes à construção ou melhoria da infraestrutura, seja por meio de políticas públicas que interferiam no deslocamento das atividades da população, acabam por transformar as funções dos lugares, consequência também da valorização/desvalorização dos lugares.

Como coloca Carlos (2007), a construção de infraestruturas acaba ocorrendo e daí decorre ou valorização ou a desvalorização do local. No caso do Lago do Abreu e áreas próximas ao local, observamos que, devido ao processo de urbanização e instalação das estruturas urbanas, ocorreu a valorização dos imóveis construídos e a especulação de imóveis que foram beneficiados com essas novas estruturas. $O$ crescimento populacional, principalmente o urbano, despontado pelo Brasil nas últimas décadas, consequentemente no município de Formosa-GO, a 
partir dos anos 1991 até 2010 (último censo realizado) ocorreu um crescimento de 62,9\% da população formosense, um crescimento de 3,3\% ao ano. Passou-se de uma população de 62.982 habitantes para pouco mais de 100.000 habitantes no período citado. Certamente esse crescimento refletiu e vem refletindo na urbanização e na especulação imobiliária do município. Os entrevistados confirmaram e reconheceram que a infraestrutura urbana, apesar de ser uns dos geradores de violência quando não passa por manutenção, é tida como um dos principais fatores desta valorização ao lado de aspectos como o lazer e paisagismo.

A esse respeito, quando foram questionados sobre como se sentiam morando nas proximidades do Lago chegou-se a respostas divergentes, desde o bem estar oferecido pelo lago e a prática de esportes ao seu redor, como também, respostas como "não faz diferença", "venderia e me mudaria sem problema", "me sinto um lixo" e até mesmo o julgamento do lago por problemas corriqueiros enfrentados pelo setor.

Sobre a paisagem como fator importante na qualidade de vida foi obtido, majoritariamente, respostas positivas, que foram vinculadas com a possibilidade de prática de esporte ao redor do Lago e a contemplação da natureza, apesar de respostas como "não faz diferença" e declarações como a fala de um morador que se sentia insatisfeito com a atual situação: "quando não tinha o Lago era melhor; agora ele virou um espaço que serve para atrair a marginalidade". Atualmente, o Lago, para a maioria das pessoas, significa o aumento da marginalidade na vizinhança em sobreposição aos aspectos de natureza, beleza, lazer e conforto.

Descuido e descaso com a paisagem, estrutura, segurança, meio ambiente e limpeza são os principais problemas levantados e foram constantemente vinculados pelos entrevistados como sendo o próprio poder público o principal gerador e até mesmo a população que frequenta e vive nas proximidades do lago. "Água empoçada", "fedor"," ratos", "daqui a pouco isso vai virar um lixão" "é só relampejar apaga tudo" (ou seja, falta energia elétrica no local), "o lago é o gerador do problema". Apesar de serem pessimistas, esses relatos são reveladores, o que implica em tamanho descontentamento dos moradores com a situação atual do Lago.

Alguns moradores utilizaram outro Lago da cidade de Formosa, com localização mais centralizada e com grande atratividade turística no município, o Lago do Vovô (latitude $15^{\circ} 32^{\prime} 27.83^{\prime \prime} \mathrm{S}$ e longitude $47^{\circ} 19^{\prime} 57.45^{\prime \prime} \mathrm{O}$ ), como um modelo a ser seguido. "Deveria mudar o lago, estrutura-lo deveria ficar parecido com o laguinho do Vovô", explana um morador. Alguns vão mais além com um tom de indignação colocando, "os mesmos impostos que eles (moradores da proximidade do Lago do Vovô) pagam, nós pagamos".

Na pesquisa, também foi solicitado aos entrevistados que atribuíssem uma nota de 0 a 10 sobre aspectos apresentados da área do Lago como a qualidade do ar, condições das ruas do entorno do objeto estudado, iluminação, tranquilidade, infraestrutura para visitação, segurança e a realização de atividades educacionais (Figura 7). 


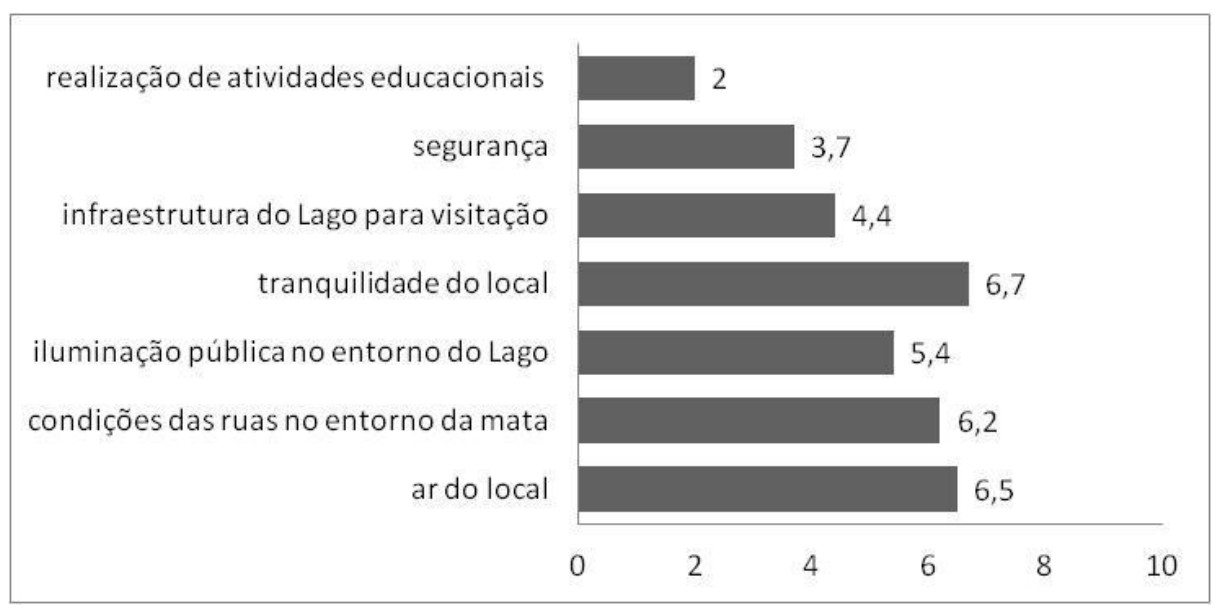

Figura 7 - Médias das notas atribuídas pelos entrevistados sobre alguns aspectos do ambiente do Lago do Abreu.

Percebe-se da análise da Figura 7 que as médias refletem o nível de satisfação da população. Os moradores acham o local tranquilo no sentido de o lugar de ser pouco movimentado, principalmente durante a semana, por isso a médias das notas foi 6,7. Mas falta policiamento no local, motivo de o quesito segurança receber uma avaliação baixa, com média de 3,7. Em estudo semelhante, realizado por Silva et al. (2012) sobre a percepção ambiental dos frequentadores da Laguna do Jansen na cidade de São Luís - MA, constatou-se que 63\% dos entrevistados reclamam da segurança pública (assaltos, tráfico, prostituição). No mesmo sentido, o trabalho de Bógea (2011), também tendo como campo de estudos a Laguna do Jansen evidencia resultados semelhantes, em que $60,6 \%$ dos entrevistados consideram a segurança local ruim e apenas $10 \%$ como boa.

O ambiente do Lago do Abreu tem grande potencial para o desenvolvimento de atividades educacionais das escolas do município, porém os entrevistados relatam que tal potencial não vem sendo aproveitado e, por isso, atribuíram notas baixas, 2,0, o que evidencia que pouco ou nada são realizados nesse sentido com a comunidade de estudantes da região, mostrando a necessidade de realização de projetos em escolas voltados à Educação Ambiental e conscientização da população local para a preservação do ambiente.

O descuido da paisagem, tais como mato alto, deposição de lixo no interior do lago, acumulo de entulhos nos lotes adjacentes, conforme evidência a Figura 4 (B), a falta de iluminação e manutenção da infraestrutura em alguns pontos, acrescidos do déficit de serviços públicos fundamentais como o da limpeza urbana justificam a média baixa $(4,4)$ da infraestrutura para a visitação local. Silva Filho (2010), ao realizar pesquisa sobre a percepção ambiental dos moradores e qualidade da Bacia Hidrográfica do Rio Passaúna no estado do Paraná, constatou percepções semelhantes, ao perguntar a moradores quais eram os principais problemas ambientais encontrado na área. Segundo o autor foram apontados problemas relacionados ao acúmulo demasiado de lixo e carência de limpeza do bairro, à qualidade da água do rio, poluição e vizinhança foram as principais citações identificadas. Outros trabalhos sobre percepção ambiental também relatam problemas de infraestrutura para com os locais pesquisados, como o Mansano et al. (2011), Addison (2003) e Bogéa et al. (2011).

Outra peculiaridade constatada acerca do Lago do Abreu se refere ao fato de ele não ser alagado durante todo o ano, pois o nível d'água não é constante e as nascentes não são suficientes para manter o Lago em nível de ocupar toda área disponível, são alguns problemas que acabam desgastando a relação dos moradores com o lago. Também há o problema da 
veiculação de doenças por meio da água local e a proliferação de insetos em especial o Aedes aegypti, o transmissor da dengue. Segundo os entrevistados, a prefeitura coloca peixes constantemente no lago, advindos de outras localidades. Assim os peixes seriam uma solução e poderiam melhorar a qualidade da água do local, porém devido ao fato de ele secar, torna-se um problema, pois segundo os moradores os peixes não são retirados e acabam morrendo, gerando mal estar visual e olfativo, como descreveu uma moradora, juntando com o fato de o lago servir como pastagem em época de seca (Figura 4A), "é uma carniça insuportável, acaba que junta peixe, com vaca e com cavalo e ninguém sabe o que é: se é um lago ou se é um pasto".

Devido à urbanização e à instalação de algumas infraestruturas, que de certo modo deveriam servir para o lazer e o bem-estar da população local, há a ideia de que acabam gerando incômodos desnecessários, segundo os entrevistados. Segundo relatos de alguns moradores, nos finais de semanas o local se torna fecundo para o divertimento das pessoas por meio da realização de eventos no local, o que acaba gerando muito barulho e incomoda as pessoas que não se propõem a participar dessas atividades.

Perguntados sobre o que mais gostam em relação à área, pode-se sintetizar que o contato com a natureza; a sensação de tranquilidade; a paisagem, principalmente quando o lago ocupa toda a sua área; infraestruturas como calçamento em torno do lago, a pavimentação das ruas adjacentes e a pracinha; a possibilidade de realizar caminhadas e praticar esportes e a constituição da família e o lar no local são aspectos que mais agradam a população local. Segundo um morador, a possibilidade de deslumbrar a paisagem do local, se torna uma sensação única que para ele "de baixo de uma boa sombra, e ar puro quem é que não gosta?".

Em contrapartida, a violência; a marginalidade; a desordem no final de semana; a poluição; o descuido com a paisagem, devido à má conservação do ambiente; o lixo e a falta de limpeza e zelo com o ambiente, acrescido com o descaso do poder público com os moradores e com o local, são os aspectos indicados pelos moradores como fatores que menos gostam na área.

Sobre essas situações e pensando em uma qualidade de vida melhor, boa parte dos moradores acredita que a área poderia ser mais bem utilizada para o lazer e para o bemestar da população. Sendo bem cuidado e zelado, recebendo os serviços públicos que atendam a demanda do local para cuidar do patrimônio público e propiciar atividades educacionais e culturais a fim de irem selar e reestabelecer relações de respeito e de identidade entre homem e o meio.

Outras propostas tais como: a exploração comercial do local, promoção de eventos, e até mesmo a diminuição do lago ou como se posiciona uma moradora, ao dizer que o local onde fica o Lago do Abreu "deveria ser aterrado", fazer uma "construção de uma escola, creche ou qualquer coisa melhor", são sugestões e novas perspectivas para transformação da paisagem.

Indagou-se também aos entrevistados a respeito do recolhimento do lixo, da limpeza do Lago do Abreu. Após a análise dos dados, verificou-se que 63,7\% acham que serviços importantes prestados pelo poder público, tais como limpeza e coleta de lixo, infraestrutura, segurança e paisagismo não são atendidos conforme a demanda da população que tem reside às margens do Lago tampouco supre a demanda quando o local recebe maior contingente de pessoas, como é o caso dos fins de semana. Mudanças de cunho estrutural, sanitária, ambiental, político e simbólica, na qual as práticas culturais e educacionais se encaixariam, são requeridos por boa parte dos entrevistados. 
No mesmo sentido, a pesquisa de Costa \& Ramires (2012) teve como local de estudo de percepções ambientais uma lagoa situada no bairro Nossa Senhora Aparecida, município de Pirapora (MG). As autoras afirmam que a ausência do poder público fez com que o local em que se encontra a lagoa se tornasse um dos grandes problemas socioambientais para a população de Pirapora, uma vez que uma ocupação local ocorreu de maneira aleatória, sem planejamento, provocando sérios danos à população devido às enchentes, construções erguidas sem auxílio técnico e, também, por estar sediado em terrenos contaminados. Dessa forma, o processo de ocupação em torno de ambiente como o lago do Abreu e a lagoa do bairro Nossa Senhora Aparecida carecem de melhoria. No caso do Lago do Abreu elas devem vir acompanhadas também da conscientização não apenas dos residentes próximo ao local, mas sim da população de toda a cidade.

Assim, observa-se que, tanto nesse trabalho quanto em outros, o Poder Público ganha a responsabilidade de tornar os ambientes mais agradáveis ou no mínimo garantir condições indispensáveis para a sua manutenção, sendo que o seu não zelo, o descuido, ocasiona um série de danos na relação dos indivíduos com o lugar. Como coloca Corrêa (1989) o Estado dispõe de um conjunto de instrumentos que pode empregar em relação ao espaço urbano, tais como: a desapropriação, regulamentação do uso do solo, controle de limitação dos preços, controle sobre os impostos fundiários e imobiliários, investimento público na produção do espaço, organização de mecanismos de créditos à habitação e outros. Assim, o poder público se destaca como um dos principais geradores urbano.

Cabe assim ao poder público como gerador equalizar as distribuições de condições e infraestruturas entre os bairros. Ousa-se dizer que a priorização de bairros desprovidos de condições mínimas de bem estar seria coerente, visando que são níveis de desenvolvimento ambíguos e talvez tomando essa postura se chegue um dia á um nível aceitável e de pouca amplitude entre os bairros. Ou seja, uma justiça distributiva territorial, que para Harvey (1980) seria uma distribuição territorial dos bens e das rendas no espaço. Sintetizando as ideias de Harvey, Moreira (2009) esclarece melhor essa ideia, que para ele se entende também como uma igualdade de oportunidades que disponha uma população de acessibilidade a um conjunto de meios e atividades necessárias para propiciar um padrão social de vida minimamente aceitável, só possível mediante melhor distribuição territorial.

Assim, devido ao Bairro em que se localiza o Lago do Abreu estar situado na periferia da cidade, necessita de planejamento e execução de ações de fiscalização do poder público, com vistas ao atendimento das demandas apontadas pela população local.

\section{CONSIDERAÇÕES FINAIS}

Cientes da complexidade que envolve o estudo da percepção ambiental da paisagem, por envolver diversos sujeitos e objetos que inventam e reinventam ou deixam inventar o seu espaço através das múltiplas determinações, considera-se as percepções dos atores sociais como únicas, frutos de relação íntima ou cotidiana com o ambiente, na qual não se pode igualar ou se anular perante as demais concepções envolvidas em outros espaços culturais.

A compreensão da percepção ambiental dos diferentes atores sociais, protagonistas da construção do cotidiano do Lago do Abreu, permitiu o entendimento de como se dá a relação deles com o ambiente, assim como fornece subsídios para uma política de preservação desse 
meio e o planejamento de projetos em educação ambiental que possam envolver ativamente a comunidade local.

A paisagem observada está em grande parte alterada, pouco ou quase nada se resta de paisagem original. Notou-se a intensidade da metamorfose do espaço que já estava habitado e o que veio a ser habitado, principalmente nas últimas duas décadas, impulsionado pelo processo de expansão urbana na cidade de Formosa-GO.

Foi perceptível a existência de relações dicotômicas em relação ao Lago do Abreu. Antes brejo, hoje "Lago", uma saudade e nostalgia de um tempo de brejo que não volta mais, ou a refutação do passado e uma visão positiva da transformação do espaço, são inferências das concepções apresentadas pelos entrevistados.

Entretanto, o que se tem quase em comum entre as concepções são o aumento da violência e a atração de dependentes químicos para proximidade da área após o processo de estruturação do Lago, e a insatisfação com o Poder Público, que em muitos casos não vem fornecendo os serviços primordiais como segurança, limpeza e zelo com a própria população, que se veem à margem do Lago, e à margem de problemas que, antes de tudo, são causas de intervenção pública, e não como uma causa natural. Além disso, o local carece de mudanças de cunho estrutural, sanitária, ambiental, político e simbólica, tendo em vista a necessidade de desenvolver atividades integrativas com o objetivo de atender os anseios da população local. Como reza a Carta Magna deste país, o meio ambiente ecologicamente equilibrado deve ser fruto de relações equilibradas na sociedade que envolvam ativamente o Poder Público e a população.

\section{REFERÊNCIAS BIBLIOGRÁFICAS}

1. ADDISON, E. E. A percepção ambiental da população do município de Florianópolis em relação à cidade. 2003. 152 f. Dissertação (Mestrado em Engenharia de Produção) -Programa de Pós-Graduação em Engenharia de Produção, Universidade Federal de Santa Catarina, Florianópolis, 2003.

2. BAY, A. M. C.; SILVA, V. P. Percepção ambiental de moradores do bairro de Liberdade de Parnamirim/RN sobre esgotamento sanitário. Holos, v. 27, n. 3, p. 97-112, 2011.

3. BRASIL. Constituição da República Federativa do Brasil. Brasília, DF, 1988.

4. Ministério da Integração Nacional. Secretaria do Planejamento e Desenvolvimento. Plano Diretor do Município de Formosa - GO. (2003). 188 p. Disponível em: <www.integracao.gov.br/.../download.asp?.../planos_diretores/Plano_Formosa $>$. Acesso em: 06 nov. 2012.

5. BARROS, J. L. A percepção ambiental dos quilombolas kalunga do engenho e do vão de almas acerca do clima e do uso da água. Ateliê Geográfico, v. 6, n. 4, p. 216-236, 2012.

6. BOGÉA, N. B. e et al. Análise da Infraestrutura da Lagoa da Ana Jansen em São Luís do Maranhão: um estudo a partir da visão dos seus frequentadores. In: Reunião Anual da SBPC, 63, 2011, Goiânia. Anais. São Paulo: SBPC, 2011.

7. CARLOS, A. F. A. O Espaço Urbano: Novos Escritos sobre a Cidade. São Paulo: Labur Edições, 2007, 123p. 
8. CARVAlHO SOBRINHO, G. M. Percepção ambiental do Lago do Vovô e da Lagoa dos Santos. 2011. 53 p. Monografia (Graduação em Geografia) - Unidade Universitária de Formosa, Universidade Estadual de Goiás, Formosa, GO, 2011.

9. CLAVAL, P. A. As abordagens da Geografia Cultural. In: CASTRO, I. E. (Org.). Explorações Geográficas. Rio de Janeiro: Bertrand Brasil, 1997.

10. CORRÊA, R. L. O espaço urbano. São Paulo: Editora Ática S.A., 1989, 94 p.

11. COSTA, V. A.; RAMIRES, J. C. de L. Percepção ambiental dos moradores do bairro Nossa Senhora Aparecida quanto à poluição da lagoa em Pirapora-MG. Caminhos da Geografia, v. 13, n. 44, p. 35-42, 2012.

12. FAGGIONATO, S. Percepção ambiental. Disponível em: <http://www.cdcc.usp.br/bio/mat_ percepcaoamb.htm>. Acesso em 19 ago. 2013.

13. FERNANDES, R. S.; PELISSARI, V.B. Como os jovens percebem as questões ambientais. Revista Aprender, v. 13, n. 4, p. 10-15, 2003.

14. FERREIRA, C. R. T. Avaliação da degradação urbana através da percepção ambiental: $O$ caso do alto da bacia do limoeiro, Presidente Prudente, SP. 2001. 102 f. Dissertação (Mestrado em Geociências) - Universidade de Presidente Prudente, Presidente Prudente, 2001.

15. FORMOSA. Decreto N. 1977 , de 20 de dezembro de 2010. Declara de utilidade pública, para fins de desapropriação, a área de terreno que menciona e dá outras providências. Formosa, GO: 2010.

16. GEHRKE, A. E. B.; RUGE, D.; FEDRIZZI, B. Percepção ambiental dos frequentadores da orla do lago Guaíba na cidade de Porto Alegre - RS. In: Encontro Nacional sobre Edificações e Comunidades Sustentáveis, 6.,Encontro Latino-Americano sobre edificações e comunidades Sustentáveis, 4. 2011, Vitória-ES. Anais. Vitória-ES: UFES, 2011.

17. GIL, A. C. Métodos e técnicas de pesquisa social. São Paulo: Atlas, 1999, 200 p.

18. HAHHAD, S.; XIMENES, S. A educação de pessoas jovens e adultas e a nova LDB: um olhar passados dez anos. In: BRZEZINSKI, Iria (Org.) LDB dez anos depois: Reinterpretação sob diversos olhares. São Paulo: Cortez, 2008. 309 p.

19. HARVEY, D. A justiça social e a cidade. São Paulo: Hucitec, 1980,291 p.

20. HOLZER, W. O Lugar na Geografia Humanista. Território, v. 4, n.7, p. 67-78, 1999.

21. INSTITUTO BRASILEIRO DE GEOGRAFIA E ESTATÍ́STICA - IBGE (2011). Operação censitária. Disponível em: <http://www.ibge.gov.br/home/presidencia/noticias/guia_do_censo_2010_ operacao.php>. Acesso em $18 \mathrm{dez} .2012$.

22. LERMEN, H. S. Percepção ambiental dos moradores vila Parque Santa Anita - Porto Alegre. 2008. Trabalho de Conclusão de Curso - Especialização em Saúde Pública. Universidade Federal do Rio Grande do Sul. Porto Alegre, 2008.

23. MANSANO, C. N.; SARRÃO, A.; SARRÃO C. Percepção da paisagem de alguns frequentadores do Parque do Ingá na cidade de Maringá-PR. In: Simpósio de Estudos Urbanos, 1, 2011, Campo Mourão. Anais. Campo Mourão: Faculdade Estadual de Ciências e Letras de Campo Mourão, 2011.

24. MARCONI, M. A.; LAKATOS, E. M. Fundamentos de metodologia científica. São Paulo: Atlas, 2011, $315 p$. 
25. MINAYO, M. C. S. Pesquisa Social: teoria, método e criatividade. Rio de Janeiro: Vozes, 2007. $108 \mathrm{p}$.

26. MOREIRA, R. O Pensamento Geográfico Brasileiro: as matrizes da renovação. São Paulo: Contexto, 2009, $173 \mathrm{p}$.

27. . O que é Geografia. São Paulo: Brasiliense, 1985, 113 p.

28. PROGRAMA DAS NAÇÕES UNIDAS PARA O DESENVOLVIMENTO - PNUD (2013). Ranking IDHM Municípios 2010. Disponível em: <http://www.pnud.org.br/atlas/ranking/RankingIDHM-Municipios-2010.aspx>. Acesso em: 18 ago. 2013.

29. SÁ, C. P. A construção do objeto de pesquisa em representações sociais. Rio de Janeiro: Eduerj, 1998. $106 \mathrm{p}$.

30. SANTOS, M. A natureza do espaço: Técnica e Tempo. Razão e Emoção. São Paulo: Edusp, 2012a. 384 p.

31.

Metamorfoses do Espaço Habitado: Fundamentos Teóricos e Metodológicos da Geografia. São Paulo: Edusp, 2012b. 132 p.

32. SILVA, A. S. Espaço urbano, desigualdade e indicadores de dimensões de sustentabilidade: análise de Formosa-GO. 2011. 277 f. Tese (Doutorado em Geografia), Universidade Estadual Paulista "Júlio de Mesquita Filho", Presidente Prudente, 2011.

33. SILVA, A. S. e et al. Percepção Ambiental De Frequentadores E Estudo Dos Impactos Do Parque Ecológico Laguna da Jansen, Município De São Luís, MA. In: Congresso Brasileiro de Gestão Ambiental, 3, 2012, Goiânia. Anais. Bauru-SP: IBEAS - Instituto Brasileiro de Estudos Ambientais, 2012.

34. SILVA FILHO, L. V. Qualidade e percepção ambiental: estudos de caso da Hidrográfica do Rio Passauna. 2010. 218 f. Dissertação (Mestrado em Engenharia de Recursos Hídricos e Ambiental), Universidade Federal do Paraná, Curitiba, 2010.

35. TUAN, Yi-Fu. Topofilia: um estudo da percepção, atitudes e valores do meio ambiente. São Paulo: Difel, 1980, 288 p.

36. TEXEIRA, R. A. Formosa: Portal do Nordeste Goiano ou polo regional do entorno de Brasília?. 2005, 167 f. Dissertação (Mestrado em Geografia) - Universidade Federal de Goiás. Goiânia, 2005.

37. UNESCO. Rapport Final du groupe d'experts sur le project 13: La perception de la quilité du milieu dans le Programme sur I'homme et la biosphère (MAB). Paris: Unesco, 1073, 79p.

38. VASCONCELOS, F. A. L. Análise comparativa da percepção ambiental e conhecimento de alunos da rede pública e particular da Região Metropolitana do Grande Recife acerca do tema "Ambientes Recifais". 2005. 70 f. Monografia (Bacharelado em Ciências Biológicas) Universidade Federal Rural de Pernambuco, Recife, 2005.

39. WAGNER, P. L.; MIKASELL, M. W. Os temas de geografia cultural. In: CORRÊA, I. C.; R. L. (Org.); ROSENDAHL. Z (Org.). Introdução à geografia cultural. Rio de Janeiro: Bertrand, 2003, 224 p.

40. WHYTE, A. V. T. La perception de l'environment: lignes directrices méthodologiques pour les études sur le terrain. UNESCO Paris, França, 1978. 134 p. 